\title{
Giovanni Sartori
}

\section{Video-Power}

MUCH OF OUR RHETORIC IS, TODAY, GLOBALISTIC. THE STATE unit, we say, is obsolete, and we are moving toward a global market with fewer and fewer frontiers. Concurrently our minds are opening themselves to a broader world, indeed to the 'other worlds' that surround our own. And the catalyst of this globalization is the enormous expansion of all kinds of communication, thereby eminently including our being able to see the world, all the world, in images in our homes in real time.

I have said advisedly that this is the rhetoric. For the reality may well turn out to be its exact reverse. While the globalizing drive is well noted and receives the applause, we are yet confronted with a forceful counter-pull that is generally glossed over, or sealed away as if it belonged to another planet: localism. To be sure, there is a localism that is a mere adding up of vested interests and, by the same token, a drag of the past. This is not what I have in mind. My referent is localism as a surging drive that counters globalism on a par, as a counter-pull of equal legitimacy: for one, the localism of 'strong democracy' - as Benjamin Barber would have it. ${ }^{1}$

The argument is, here, that 'real democracy' can only be, and must be, participatory democracy. How? Well, at a minimum by bringing politics home to the people, by maximizing constituencycentred politics. The former Speaker of Congress, Tip O'Neill, said it with unabashed candour: 'all politics is local politics'. What he had in mind was not, presumably, 'all politics', but the overwhelming reality of pork-barrel politics. There was a time, not long ago, when such a dictum, true as it might have been, carried with it a regret, an 'alas'. Tip O'Neill said it without blushing. That all politics is local politics must have appeared to him not only an obvious truth, but also a virtuous one. Indeed it would be hard to deny that

\footnotetext{
1 Benjamin Barber, Strong Democracy: Participatory Politics for a New Age, Berkeley, University of California Press, 1984. Note the subtitle.
} 
constituency-centred politics does bring government close (closer) to the people, that it is, as such, the manifestation of an advanced (more advanced) democracy, and that it comes with, and speaks for, greater participation. Indeed, participation and localism grow in unison. This is so because the citizen truly participates, i.e., 'takes part' in the meaningful sense of the notion, where he lives and votes; and in voting-participating for himself, for his own interests and needs, he equally stands for the place in which he lives. The gist is, then, that to bring politics to the people is to bring politics into the locality in which they live; that the greater the localism, the greater the power of the demos; and that locally-placed politics is also, almost inevitably, locally-minded politics.

For my argument the two contrary pulls which characteristically mark, in our time, the march of history are best conceived broadly and allusively. Let the definitions be: localism is to concentrate oneself within the village; globalism is to decentralize oneself towards a limitless world. In slogan form: localism is me, here, immediately; globalism is others, everywhere, over time. Which one of the two pulls has a superior claim? Even if we bring in the democratic legitimation of localism - the argument that constituency-centred politics expresses 'strong democracy' - even so I would still hold that the case for globalism is the superior one. Strong democracy results from feeble theory. It is not difficult to show, that is to say, that 'strong theory' supports a different case. In the late 1960s Dahl wrote a delightful piece, Democracy and the Chinese Boxes ${ }^{2}$ whose central question was: which is the unit? The city? The nation-state? Our planet itself? Is there an optimal unit? Dahl's suggestion was to think about appropriate units of democracy as 'a set of Chinese boxes' (p. 373), bearing this crucial caveat in mind: 'the argument for larger units does not destroy the case for small units. What it does is to make a ... radical shift in the nature of the argument' (ibid.). Quite so: each unit allows for a different theory of democracy. In Dahl's own words, "we may need different models of democracy for different kinds of units' (p. 375). Thus, the argument for the small unit does not destroy the case for the larger

2 Originally Dahl's presidential address printed in the American Political Science Review, December 1967, pp. 953-70, under the title, 'The City in the Future of Democracies'. I quote from its abridgement in H. S. Kariel (ed.), Frontiers of Democratic Theory, New York, Random House, 1970, pp. 370-94. 
unit: the smaller Chinese box still is part and parcel of ampler encapsulating boxes.

However, a superior claim in theory need not be a winning claim in practice. In the real world the good case is often lost and the bad cause often prevails. Let us first assess, then, the extent to which localism has already penetrated the democratic political process. This development is mightily under way in the United States, and may thus be usefully underpinned with reference to its most advanced case.

The single major reason for the greater headway of localism in America vis-à-vis Europe lies in the solidity of the parties. European parties have long been, as a rule, more centralized, more organization-based and, all told, far stronger entities than their American counterparts. Hence European parties are in a far better position to resist the centrifugation of localism. American parties have never been, nationwide, much more than labels (though powerful ones). Even so, they are currently in a shambles, worse off than ever before: they are incumbent-serving outfits dismembered constituency by constituency. Why is that? Three factors have contributed to this splintering of American parties - both at the state and federal levels - into a multiplicity of candidate-centred and grass roots district-gravitating fragments. Two are long-standing ones: the single-member district system, and the roll call, the record of how each member votes on each issue in the Houses. The third factor is new, and is the catalyst of the whole process - it is (as will be explained shortly) video-politics.

To be sure (England well attests to the point) single-member districts with plurality voting do not necessarily tear the party apart. The organizational mass party whose parliamentary members are subject to party discipline did succeed, in the early decades of our century, in transforming the fragmented party of notables (in which each notable was the king-maker of himself) into a unified entity that took charge of the king-making, of selecting and getting its candidates elected. But the American parties never quite made this turn from the personalized (notability or personality-centred) party to the 'abstract' (programme or platform-based) organizational mass party. They remain, therefore, defenceless and highly exposed to whatever happens in their environment. And since party undiscipline, rather than party discipline, is the American hallmark of Congressional behaviour, the roll call uncovers what voting along 
party lines covers up: it leaves each member 'naked' vis-à-vis his electors. No doubt, it is nice to be independent. But this was a privilege of the Burkean representative. The American representative simply substitutes party-dependence for constituency-dependency. Mind you, my intent is not to praise PR, multi-member constituencies, party discipline, or whatever makes European politics different from American politics. My intent simply is to restore the balance of the pros and cons. And the point is that with list systems of proportional representation, the representative must relate to, and stay in tune with his party at least as much as with his electors. Here, then, the weight of localism is countered by the weight of party - a countering that the American political system does not provide.

So, the United States eminently is the country where national politics turns out increasingly to be a 'rainbow aggregation' of myriads of village-centred and local-minded pressures and counterpressures. ${ }^{3}$ This remains the case even with regard to national sacred cows: the elderly, pensions, health services. The fact that these are nation-wide untouchables does not detract from the fact that they represent a sum total of local sacred calves that tip the balance of victory (or defeat) in every constituency. In the USA more than elsewhere, woe to those who fail to protect local interests; woe to those who agree to the closure of a factory; in the farming states, woe to those who do not protect agricultural interests; and the same member of parliament who trumpets to the four winds that military expenditures must be drastically cut, resists with all his might the shutting down of a truly useless barracks in his protected territory. Whatever the rhetoric, the practice is narrowly protectionistic. And it is no paradox that it is the Democrats who have taken the lead in a hitherto 'unprogressive', indeed capitalisticconservative, advocacy of protectionistic economic policies. As I was saying, it is the maximization of democratic participation which both legitimizes and nurtures, in the aggregate, an introverted, 'closed' national state whose priority is to look after the boys (and/or girls) at home and in their homes.

The question was: will localism (and what flows from it) win? It might; but, if so, not on the aforementioned grounds alone. The

3 Luciano Pellicani puts it very well: the United States is a polity 'rich in micro-deciders and poor in macro-deciders' (Biblioteca della Liberta, XXI, 1986, p. 29). 
ulterior and decisive factor is, as my title says, video-power. And here enters the technological element of the game, 'the ghost in the machine'. My sense is that the pull of localism is redeemed, but not yet turned into a winning pull, by the participatory maximization of democracy. If localism will prevail (an apprehension, not a prediction), it will prevail because it is enforced upon us, insidiously and obliquely, by the force of the video. ${ }^{4}$

Television brings to us, in our homes, the world 'seen' in pictures, the world-in-images. This is the greatest anthropological revolution of all times. The passage from writing by hand to the 'Gutenberg galaxy' (the print culture) is but small, compared to the leap from the Gutenberg galaxy to what we might call the 'McLuhan galaxy', to the birth of ocular man moulded by what he sees. I recall McLuhan also because we are indebted to him for the felicitous coinage of the notion of the 'global village'. For McLuhan, the global village gives rise to an implosion which intensifies to the utmost responsibility. I have my doubts about this. It is surely the case, however, that the global village is the globe which becomes a village, which 'villagizes' and 'parochializes' itself, which breaks itself up into thousands of small and peripheral homelands. ${ }^{5}$ For the last two centuries, the fatherland, the patrie, was France, Germany, Italy - the nation-state unit. It now reverts to being what the Abbé Galiani humorously called (in the cosmopolitan vein of the Enlightenment) 'a huddle of houses inhabited by cuckolded

4 It should be clear that my notion of localism does not contradict the standard argument that television 'homogenizes'. Regardless of how much our life styles, tastes and thinking capabilities (or incapacitation) are rendered globally alike, we can still be home-centred and ego-serving. Indeed, as we all become equally garbage-sensitive, we all want our garbage dumped elsewhere (not in our neighbourhood). And if we all equally desire to become rich and famous, it is rational for each of us to leave others in poverty and obscurity.

5 In media terms this is rendered by the tenets that 'people want . . . things relevant to their own lives', and that 'an event must be close to home' (Doris A. Graber, Mass Media and American Politics, Washington, D.C., Congressional Quarterly Press, 2nd ed. 1984, pp. 78-9). The localistic feature is not at odds with the 'no sense of place' one (the theme subtly pursued by Joshua Meyrowitz, No Sense of Place, Oxford University Press, 1985), with the argument that by 'merging discrete communities . . . television has made nearly every topic and issue a valid subject of interest and concern for virtually every member of the public' (see esp. pp. $307 \mathrm{ff}$ ). One can be locality-centred in the political pursuit of one's own concrete interests, and also get involved in 'placeless' issues. If so, what is to be feared is a 'plural simultaneity' of both 'my place' and placenessness which squeezes out the national public interest agenda. 
barons'. The barons (with or without horns) have given way to the animal loquax, to talking animals whose privilege is indeed to talk; but the "video unit" is again very much a huddle of houses; and the screen is filled, around the clock, with people-aptly sampled according to sex, age, colour and distribution of opinion - forced by a pestering interviewer to say something, anything at all. This is not quite demo-power; but it does look as 'giving voice', concrete voice, to the voice of the people. Good. Or, better, it must be the case that many people feel good about it.

Should they? Let us be warned. The world displayed by the screen is not just the world of real people; it is also, and far more importantly, an amputated and deeply distorted reality. To begin with, the global village is not global at all. The globe on television is only the world where television is freely admitted. But in at least half of the globe television is not permitted to enter and/or exists only as a propaganda monopoly. This does not only mean that half of the world remains unseen by the other half; it also entails that the viewers of the free countries are led to judge of world events according to double, misleading and unjust standards. South Africa becomes a monster (a terrorist state, according to the Reverend Jesse Jackson), whereas the African states to its north (all the way up to Libya) ruled by military dictators, and where true massacres have indeed taken place, sit on the bench of the accusers and of the judges. Israel would not fare much better were it not for the support of the Jewish diaspora; and even so Israel appears on the screen in a worse light than Syria, Iraq or Iran, countries dominated by ruthless tyrants. Thus, free countries are sitting ducks for television to shoot at, while unfree countries in which people can be slain with the ease we kill mosquitoes are immune ducks which the video leaves unscathed.

There is more to it than that. Walter Cronkite, the anchorman of American television, relinquished written journalism in favour of 'image journalism' on the claim that the latter furthers 'objective information': pictures, he held, do not lie and speak for themselves. I fell for that argument too-- but briefly. Man's capability of lying being equal - regardless of the medium - pictures can lie with infinitely greater effectiveness than has hitherto been the case with written journalism. For one thing, it is much easier: the lying is left to the scissors. You select one image out of one hundred; and you have a much better alibi for discarding the remaining ninety-nine 
than the journalist whose lines are not as scarce as TV seconds. Then, do pictures really speak for themselves? Hardly so. We are shown a dead body. Who is the killer? For that we must rely on the speaking of Cronkite. I do. But if one has to rely on the speaking, e.g., of Goebbels, then I would not. People who were around in the 1960s all remember the picture of a South Vietnamese colonel shooting a Vietcong in the temple. We were all horrified. However, what were not shown by the picture were all the surrounding mutilated bodies of marines, women and children who had been slain shortly before by the Vietcong. Did the first picture lie? No - but also, and more fundamentally, yes. To borrow from the jargon of the day, I am more an essentialist than a contextualist. Even so, I am appalled by the extent of decontextualization that goes with the 'picture that speaks for itself.

Distortions aside, the members of the Gutenberg galaxy, that is to say, the people brought up in the era of newspaper reading, have been reading every day of, say, some twenty events of nation-wide and international significance. These twenty events (of, say, one printed column each) are reduced by the evening news of mass networks to, say, about ten and rushed through (indeed, the insiders call them 'moments') in some 45 seconds per item. The compression-omission is staggering, and becomes truly gigantic if one pauses to consider what it is that the image itself, on account of its very nature, omits. The image records the here and now - that is it. In the television galaxy Diogenes's lantern has nothing to seek: problems (what, indeed, is a problem?), the general interest, the long view, are 'abstractions'. What exists is only what can be seen, above all what strikes the cye: storms, death, fire, violence, protest, arrest, whiners. Most of it is the dramatization of the trivial joined to the atrophy of the understanding. The man who reads, the Gutenberg man, is forced to be a mental animal; the man who just watches is only an ocular animal. The impoverishment promises to be of devastating proportions.

Granted, it is not the case that all the media, everywhere, are actually performing as recounted above. There are very great differences, across Western countries, in the media coverage of world events. For instance, England and all the European countries with which I happen to be familiar, are to date more serious, or less entertainment obsessed (in politics) than the three major American networks (ABC, CBS, NBC). In the United States 'television news 
is for the most part merely a branch of show business. Its values are those of drama, pathos, and titillation'. ${ }^{6}$ This would not hold true, so far, for the Western world in general. Let us therefore leave generalities aside and stick to the specific case of the United States - a 'worse case', but still the first one in importance.

There are three features which strike me as being characteristic (though not exclusively so) of today's American television. The first is the salience acquired by protests - grievances, demonstrations, contestation, strikes - and the manner in which they are handled. Giving voice to voice surely is a good cause. Its goodness largely depends, however, on how fairly voices are screened and portrayed. American television prides itself on providing 'straight news', of being, as much as is humanly possible, unbiased. But if the video spokesperson really believes this, then he is duping himself. The impartial treatment of protest would require the hearing of both sides, the admission of contra-diction, of he who denies what another affirms. This is very seldom the case. The more serious the matter, the more, day after day, the video is at the service of the accusers, of the attackers. The case of those who are being attacked is seldom heard.

The preferring of the attacker, and its redeeming principle that the media must be adversary, goes back at least twenty years, and is by no means confined to television. In 1969 I became (alas) the Dean of the Political Sciences Faculty in Florence, and the going was rough. The New York Times sent a correspondent to Florence who apparently cruised around me for days interviewing students (preferably, it turned out, the agitated ones, even terrorists-in-themaking). I never saw him. At the time I had already been a visiting professor at Harvard and Yale and hence 'had a name', one would presume, where the paper was read. No matter. The New York Times published a highly inaccurate story which did talk a lot about a person (me) who had never been talked to. Within 'all the news fit to print' I was evidently unfit. And this manner of reporting has become a standard one with televison. While it remains a legacy of the debunking of the $1960 \mathrm{~s}$, the fact remains that 'pictures' inherently privilege protests (and help to activate them: we see all the time agitations and agitators by appointment, waiting for the cameras to arrive in order to begin agitating themselves). Often, also, what we

${ }_{6}^{6}$ Geoffrey R. Stone, in Bulletin of the American Academy of Arts and Sciences, February 1987, p. 20. 
are given is just the protesting action itself. Just before the Olympic Games in South Korea, evening after evening we were shown pretty nasty students throwing not only the ritual stones but Molotov cocktails. What were they demanding via inflammables? The networks never said. While the medium is, in itself, a grand simplifier, the medium-maker just goes along and seemingly cares little about explaining why it shows what.

The second feature, and a more uniquely American one, bears on the display of what might be called 'false statistics'. In its mild form - the casual interviewing - it simply magnifies and attributes meaning, misleadingly, to meaninglessness. Is a nuclear plant dangerous? How dangerous? Should it be closed? Ask around. John or Jane Doe, of ZYW news, in Niagara Falls, Death Valley, Nevada (seconds are precious, but not for the hammering of such vital information) walks down Main Street, interrogates a handful of bystanders, and will end up with broadcasting five yeses and two noes. The message implicitly is that public opinion wants the plant to be shut down (with the two noes attesting that democracy is never unanimous and that the interviewer did not tamper with the evidence - even though he did by choosing). In similar fashion, suppose that the President of the United States decides that a human colony should be placed on the moon. As the decision is announced, every effort will be made to exhibit on the screen an old lady in poor health who says that it is shameful to spend money on a lunar base when she cannot pay for a decent home. So, it is one against one. It ought never to be the case (honni soit) that any decision should pass unchallenged-- except that the President of the United States has perhaps earned access to television on account of having won an electoral marathon that would kill most ordinary joggers. But how did the old lady get to the screen? On what credentials? Does she represent the voice of the people? If we are led to believe that, then we are being mightily misled. And so we are.

It may be argued that the above is little more than folklore. But let us move on to the 'false statistics' which truly take statistical form and which display soft, and often utterly invalid evidence, in the guise of 'hard evidence'. Take, for example, the way Americans are given proof of discrimination against blacks. Blacks certainly are underrepresented - in proportion to their demographic proportion - in colleges, Wall Street, Congress and, say, among millionaires. Does this prove that the 'cause' of their underrepresentation is discrimination? Of course not. Any kid taking a kindergarten 
course in statistics would know better. For instance, in a number of sports American teams are disproportionately black. Does this indicate that in athletics, boxing, etc. whites are discriminated against? This, everybody would say, is a stupidity. Yet its reverse, which is just as stupid, inundates the media and - amidst so much challenging of almost everything - goes unchallenged.

The third feature is what I call the 'poll trap'; a trap that adds up, often enough, to outright poll cheating. The point is that the daily bombardment with and by polls has brought about a 'poll-direction' (a variant of Riesman's other-direction) which is nothing other than a reflection-effect, or an echo-effect, of what the media themselves have been suggesting. During the course of the IranContra scandal, pollsters provided around-the-clock figures on how many people believed that President Reagan was as innocent as he pretended. How would the ordinary person know? Clearly, the responses reflected what the media had been incessantly and unanimously hinting, namely, that the President 'had to know'. I can see that this is how it should be, since it is the only way it can be. But I am dismayed by the camouflage, by the hypocrisy (or the hard-tobelieve naiveté) of presenting the poll evidence as being the voice of the people. Polls are a play-back. What the polls reveal merely is, in cases such as the Iran-Contra affair, the extent to which the media are able to create the opinion which is then impudently displayed as a vox populi, vox Dei verdict. The God of the matter is a feedback loop. The alleged voice of the people largely is the voice of the media in the people. This is, I have conceded, the only way it can be. If so, however, the pretence that public affairs are brought to, and decided by, the 'people's court' cannot carry the extra weight with which it is endowed by the 'media-pollsters complex'.

Once the 'trap' and the cheating element of the process are unmasked, why should politicians be as poll-directed as they are? It is doubtless the case, in the United States, that policy (mind you, policy decisions, not merely electioneering) is powerfully conditioned by poll-listening. Politicians and their advisers live around the clock with the stethoscope in the ear, in perennial poll-anxiety. Should they? I submit that it is quite unnecessary. Politicians have been misled into believing that what the polls reveal is a firm and definite state of opinion. Not true; most of what they reveal is fluff. For one thing, the intensity with which an opinion is held is seldom 
probed (at least, by the media-serving pollsters). Secondly, statistical prevalences are largely made of opinions of people who have no opinion (until the interviewer forces them into expressing one), or are in constant opinion flux. ${ }^{7}$ Thirdly, poll findings are highly manipulable and largely depend on how the questions are phrased. For instance, asking whether abortion should be prohibited or whether the right to life of the unborn child should be protected is asking the same question, and yet 20 per cent of the respondents respond differently. Thus, in matters in which our own shoe does not pinch and our ignorance is crushing, the pollster actually taps noises, not messages. No matter; for the $n$ s to be right, noises and messages are made equal and thrown together into the heap. So, fluff.

Turning to poll-direction, let the example be the issue of the allegedly incurable federal deficit. Assume a Rawlsian veil of ignorance, that is, a legislative body insulated, like a jury, from whatever might prejudge and bias its best judgment. And assume, to make it short, that the figure is 200 billion dollars. Is that amount as intractable as we are told? Well, the deficit in question could be easily handled, for instance, just by making Americans pay for their oil as much as, on average, Europeans do. It is estimated that a tax of one added cent on gasoline equals one billion dollars a year for the Treasury in Washington; and that if the price at the pump were to rise to $\$ 2.79$ a gallon (the average price in Europe) the Treasury would collect some 150 billion dollars. As the oil spot prices drop (as they have often done before), the Treasury might even collect 200 billion dollars in just one year. But no, this is unthinkable, it cannot be done. Why? Because all members of Congress (for once unanimous) say that 'public opinion is against', that Americans want to pay as little as they do for petrol. So what? The buyer always desires to pay less for everything (just as the seller always likes to sell for more). I too am happy to pay less for my gasoline. Even so, to let petrol pay off the deficit is a sensible thing to do (for other reasons as well, such as reducing dependence on foreign energy resources, discouraging waste, lowering pollution). We are,

$7^{\prime}$ For an array of ten prominent general political issues that confront the country in any given year ... the average cirizen is likely to have a strong and consistent preference on perhaps one or two of them, and virtually no opinion whatsoever on the rest. Yet when an eager survey research interviewer ... starts to ask ... opinions are invented on the spot' (W. Russell Newman, The Paradox of Mass Politics: Knowledge and Opinion in the American Electorate, Harvard University Press, 1986, pp. 22-23). 
then, simply up against 'poll paralysis'. Assume, however, that in a split second of unprecedented valour Congress did unanimously vote, across party lines, a substantial gas tax. How could it be punished? How would the allegedly angry consumers take their revenge on their representatives? I am prepared recklessly to predict that if the bluff (poll-terror) was called, nothing would happen. Remember, the vote in Congress was unanimous: there were no good guys, they had all been equally bad. Would all, then, lose their seats? Consider, on the other hand, that the voter has just one vote. A couple of years after the enactment of the gas tax, will the gas issue be the only overriding one that matters to him or her? I doubt it. And I equally doubt that whoever challenges the incumbents would do so on the single pledge of repealing the gas tax. On top of other considerations, at the moment gas will be more expensive but, in compensation, the deficit scare will be over.

The moral of the hypothetical story is that poll-terror is excessive, often unjustified, and just as often counterproductive. Pollinduced demo-power (which easily is, in reality, video-power over the people) paves the way to non-decisions, or conversely to wrong decisions conditioned by mere rumours, by false statistics, by the blowing up of the trivial, and, last but not least, prompted by the 'here and now' of thousands of little homelands.

An interesting question is how did it happen that the US has become the worst case, that the American media have tumbled to the level of poverty which I have been describing? Our conventional wisdom is that a pluralistic-competitive media structure is selfcorrecting, that the media-consumer would end up punishing the worst news provider, just as it punishes the worst car producer. But it does not seem to work that way. Aside from the Wall Street Journal, which is a technical paper, USA Today has managed in a

8 Let it also be noted that while video-power is in no small part responsible for a number of decisions, the media's own responsibility is never admitted. The Iran arms-for-hostages deal was largely prompted, in the mind of a post-Gutenberg President, by the continuous showing on TV of the families of the hostages weeping and denouncing the insensitivity of the White House. However, when the scandal exploded, the media mercilessly went after the (undeniable) stupidity of the President, never acknowledging that they were, if mindlessly, its originators. Similarly, in presidential campaigns the ever growing complaint is that the candidates are not issue-focused. Is it their fault? In part, they are advised to shun issues by their pollsters and media advisets. But it is also the very TV journalists who make the complaint who generally ignore issue statements unless they can be quoted as blunders or factual mistakes. Even though it does not cross their minds, the blamers themselves are far from blameless. 
few years to beat the New York Times in sales, thus becoming the national daily, in circulation and distribution, of the average American. USA Today is, as is known, an opinion monitored paper: it prints what the public (according to market researchers, to pollauscultation) wants it to print. If so, the unbeatable shallowness of USA Today sadly attests to one of the shallowest public opinions of the Western world. And TV follows suit. Its alibi for its equally unrivalled shallowness is that the public must be 'entertained' and that what drives it down is precisely the need to compete and remain competitive. How and why can that be?"

Is it the case that in media matters competition does not display the virtues which it displays in economic matters? However, the doubt that creeps in to my mind is whether the three American networks truly are competitive. Since I get nothing out of them in terms of information, I generally browse among their respective evening news to discover what is news, and newsworthy, for each. To my unending astonishment, some eight news items out of ten are exactly the same across allegedly rival channels. If that is competition, it looks more like collusion. The safe game in town seems to be that everyone should turn out much the same copy. This is so, it could be argued, because the media themselves are victims of the 'poll trap'. The news producer tells us that he must give the consumer what the consumer likes. On this premise a viscious circularity-like an 'opium vortex'-sets in. It is first discovered that people like opium; the opium is given, and thus more people like more of it; and we finally obtain a population that wants opium only. But why are Americans far more opium-addicted (to pursue the metaphor) than other people? Are Americans born ethnocentric? Are they born incapable of understanding what other

${ }^{9}$ The story itself has been profusely chronicled. Bill Moyers, one of the few serious journalists to resist the tide, tells of the downgrading of CBS News as follows: "we began to be influenced by the desire to please the audience. The object was to "hook" them ... Pretty soon, tax policy had to compete with stories about three-legged sheep, and the three-legged sheep won ... And now we're trapped. Once you decide to titillate instead of illuminate, you're on a slippery slope ... you become a video version of the drug culture and your viewers become junkies'. ('Taking CBS News to Task: Bill Moyers Blasts its Show-Business Approach', Newsweek, 15 September, 1986.) Thus (I now quote Peter J. Boyer, from The New York Times Magazine, 28 December 1986, p. 18) 'an unemployment report from Washington might be cursorily treated or ignored in favour of a correspondent's piece from the gates of a factory showing the grief of an out-of-work father at Christmas... And the correspondents learned that the way you got on the air was to write a snappy script and be entertaining'. 
audiences understand? Is it a law of nature that Americans are not interested in the world events that interest non-Americans? Of course not. The news missed by the newsmaker (possibly because it is not 'new') is that it is the producer who moulds the consumer. Without news-coverage there would be no interest in what is not covered. If the newscasting is designed for 'simpletons', then it will follow that 'complex' news is not understood. As the vortex develops itself, the point is reached at which the tube simply makes the watcher a mirror image of itself. At that moment the explanation for a competition without competitive benefits would be straightforward: the force of the video is forceful to the point of not allowing consumer retaliation. Has that stage been reached? Let us hope not. ${ }^{10}$

Putting two and two together, the United States turns out to be the country that bows most to public opinion (via poll-monitoring), and yet the country that has probably less public opinion worthy of its name than any other Western democracy. ${ }^{11}$ Public opinion is not only an ensemble of opinions in and of the public, but also a cluster of opinions on and about things public: the res publica, the common weal, the general interest. ${ }^{2}$ But American public opinion receives a highly inadequate feeding on American public things, and almost no feeding at all on world-wide affairs. ${ }^{13}$ This

10 While the above seems to suggest that a mixed private-public TV system is preferable to a purely private one, a simple and sufficient remedy might be to prohibit commercials on prime news time. Nothing much would be lost if, under this restraint, a network decided to go news-less (but that would tarnish its reputation even more than its revenues).

"Neil Postman, in his very thoughtful book, confirms: 'Americans are the best entertained and quite likely the least well-informed people in the Western world' (Amusing Ourselves to Death: Public Discourse in the Age of Show Business, New York, Viking Penguin Inc., 1985, p. 106).

12 discuss at length this point and opinion formation in general in the Theory of Democracy Revisited, Chatham, N.J., Chatham House, pp. 92-110.

13 This applies to print media no less than to TV. No Western capital city newspaper covers international affairs as little as the Washington Post. In general, 60 per cent of an American newspaper goes to advertising, just a 4 per cent consists of national and international news, and only part of that little is of a political nature. The comparative statistics (advertisement aside) are as follows: 'on the average... it [foreign news] constitutes only 11 per cent of all stories in American newspapers . . . By contrast foreign affairs news takes up . . 24 per cent in Western European newspapers . . . Foreign affairs coverage is limited even in elite American newspapers. For instance . . . in 1977 . . only 16 per cent of the New York Times coverage was devoted to foreign affairs compared with . . 44 per cent in the German Die Welt'. (Quoted from D. A. Graber, Mass Media and American Politics, op. cit., p. 303.) As for TV, I distinctly remember an evening in which Brokaw's NBC's alleged World News consisted, in all, of body counts: people killed in Algeria, Israel and South Africa - that was it. 
state of poverty of American public opinion is well known and documented. Some 20 per cent of Americans aged 18 to 24 cannot locate their country on a world map; a staggering 75 per cent of adult Americans were found unable to locate the Persian Gulf, 45 per cent could not find Central America, and 25 per cent missed the Pacific Ocean. And so on and so forth. This is, to be sure, mere geography. Still, on these premises it appears pretty cheeky to put on the air the verdict, e.g., that most Americans either want or do not want American warships in the Persian Gulf. But two and two are not added up. The schools are blamed. They well deserve it - but not alone. The life process is one of continuing education, assuming that the media take over where the schools leave off. But the American mass media do not take on an educational role. News is man that bites dog.

I began by asking whether we are actually moving, as we are triumphantly told, toward globalism, toward larger-than-state units that take on a world-integrated perspective. I have noted instead that broadcasting has actually nurtured, in the United States, 'narrowcasting', including therein the village-centring of politics and, ultimately, a public opinion without 'public contents'. Along the way the point that emerges is, however, an even more crucial one. Regardless of localism, we are witnessing, without adequate recognition and alertness, ${ }^{14}$ a fundamental transformation of the human condition itself, namely, the erosion of print culture and its substitution by a video culture incapable of mental abstraction. Thus, little by little, local-mindedness progresses into blank-mindedness. ${ }^{15}$ While we bicker on who controls the media, the medium per se, by the force of its own technological imperative, controls the very shaping of homo sapiens. It all began with homo prensilis, with an animal whose hand was not only capable of grabbing (prensilis) but also of manipulating and fabricating (homo faber). At the end of the cycle, are we arriving at the touch-button (no longer prensilis) man whose mental horizon is the eyeball?

14 Indeed, our recognition generally is rosy-hued. In Newsweek 17 November 1988 one reads: 'The era of TV II promises more of everything: more freedom, more control, more options' (p. 86). Clearly, 'more freedom' is here just the same as 'more options', and one wonders whether more of the same show biz and 'vidiotics' adds up to anything. As for 'more control', I am at a loss: more control of the viewer over whom or what? This is fuff in writing.

15 That these apprehensions are not upheld, to date, by confirming evidence does not $e 0$ ipso entail that they are disconfirmed. My sense is that our research designs have yet to confront the problems that I am addressing. 